\title{
Synchrotron-based crystal structure, associated morphology of snail and bivalve shells by X-ray diffraction
}

\author{
D.V. Rao ${ }^{\mathrm{a}, *}$, G.E. Gigante ${ }^{\mathrm{a}}$, Y. Manoj Kumar ${ }^{\mathrm{b}, \mathrm{c}}$, R. Cesareo $^{\mathrm{d}}$, A. Brunetti $^{\mathrm{d}}$, N. Schiavon ${ }^{\mathrm{e}}$, \\ T. Akatsuka ${ }^{\mathrm{f}}$, T. Yuasa ${ }^{\mathrm{f}}, \mathrm{T}$. Takeda ${ }^{\mathrm{g}}$ \\ a Science Based Applications to Engineering (SBAI), Universita di Roma “La Sapienza”, Via Scarpa 10, 00161 Roma, Italy \\ ${ }^{\mathrm{b}}$ Department of Physics, University of Arizona, Tucson, AZ 85721, USA \\ ${ }^{\mathrm{c}}$ Department of ECE, Rajiv Gandhi University of Knowledge Technologies, RK Valley, A.P., India \\ ${ }^{\mathrm{d}}$ Istituto di Matematica e Fisica, Università di Sassari, Via Vienna 2, 07100 Sassari, Italy \\ e Hercules Laboratory, University of Evora, Portugal \\ ${ }^{\mathrm{f}}$ Department of Bio-System Engineering, Faculty of Engineering, Yamagata University, Yonezawa-shi, Yamagata 992-8510, Japan \\ ${ }^{\mathrm{g}}$ Allied Health Science, Kitasato University, 1-15-1 Kitasato, Sagamihara, Kanagawa 228-8555, Japan
}

\section{H I G H L I G H T S}

- Synchrotron-based XRD has been applied to shells.

- Investigation of crystallographic phase composition.

- Understanding of structures at molecular level.

- SEM to explore the morphology of the snail and bivalve.

- Extraction of the lattice parameters of the mineral $\mathrm{CaCO}_{3}$.

\section{A R T I C L E I N F O}

\section{Article history:}

Received 2 May 2016

Received in revised form

11 June 2016

Accepted 21 June 2016

Available online 23 June 2016

Keywords:

Synchrotron

Diffraction

X-rays

Shells

Calcium carbonate

Morphology

\begin{abstract}
A B S T R A C T
Synchrotron-based high-resolution X-ray powder diffraction spectra from the body parts of a snail and bivalve $\left(\mathrm{CaCO}_{3}\right)$, have been recorded with Pilatus area detector. Experiments were performed at Desy, Hamburg, Germany, utilizing the Resonant and Diffraction beamline (P9), with $15 \mathrm{keV}$ X-rays $(\lambda=0.82666 \AA)$. The external shell of these living organisms, is composed of calcium carbonate, which carries strong biological signal. It consists of some light elements, such as, $\mathrm{Ca}, \mathrm{C}$ and $\mathrm{O}$, which constitute part of the soft tissue and other trace elements. The knowledge of these diffraction patterns and hence the understanding of structures at molecular level are enormous. The application of synchrotron radiation to powder diffraction is well suited for samples of biological nature via changes in their patterns and also to investigate crystallographic phase composition. With the use of Rietveld refinement procedure, to the high-resolution diffraction spectra, we were able to extract the lattice parameters of orthorhombic polymorph of $\mathrm{CaCO}_{3}$, the most abundant mineral produced by these living organisms. The small size of the crystallite is a very important factor related to the biological structure. The natural model presents a combination of organic and inorganic phases with nanometer size. For the present study, we also used the scanning electron microscopy (SEM) to explore the associated morphology of the snail and bivalve.
\end{abstract}

(c) 2016 Elsevier Ltd. All rights reserved.

\section{Motivation}

Basic knowledge of the crystal structural and the associated morphology from samples of biogenic nature, for example, from snail and bivalves, can be achieved, with the use of high-resolution X-ray powder diffraction (XRD) (Bragg, 1924) and Rietveld

\footnotetext{
* Corresponding author.
}

refinement method (Rietveld, 1969). One such method is X-ray diffraction (XRD). It has been utilized in many scientific disciplines, such as, in physics, chemistry, biology, engineering and medicine. It has become a powerful and indispensable tool in the above scientific fields, where knowledge of the relations between crystal structure, functions and properties play an important role. In recent years, high-intensity synchrotron sources, synchrotron-based beamlines specialized for diffraction experiments, techniques and software for data analysis, open the new horizons and new science 
using XRD. These new sources and techniques, further strengthen the applied sciences, as well as engineering sciences. XRD, has been used as an essential scientific tool by more than thirty Nobel laureates, for their discoveries. Researchers, published, series of papers on novel diffraction methods enabling visualization of the interior structure of crystalline materials from the millimeter down to the nanometer scale.

The real thrust of the research is to study the contribution of the calcium carbonate in external shell, operculum and soft tissue of the invertebrates (Jackson et al., 1988; Kamat et al., 2000). These shells are equally important for basic biological research and for monitoring environmental contamination. The structures are made up of pure calcium carbonate, with a very small amount of an organic matrix. The bivalve shell offer a great potential as environmental proxies, since they have a wide geographical range. The bivalve has attracted considerable and detailed attention due to its great longevity ( $>500$ years). Mineral formation is widely observed in living systems, with principle elements being $\mathrm{Ca}, \mathrm{Mg}$, $\mathrm{Si}, \mathrm{Fe}, \mathrm{Mn}, \mathrm{P}, \mathrm{S}$ and minor trace elements of Sn, Mo, Mn, Cd, Ti, B, $\mathrm{Pb}, \mathrm{Au}, \mathrm{Ag}, \mathrm{Ni}, \mathrm{Co}, \mathrm{Bi}, \mathrm{Cu}, \mathrm{Sr}$, and $\mathrm{Rb}$. These shells are largely made up of microscopic shells and contain important chemical clues to the environment in which the animal lived, such as temperature, ocean $\mathrm{pH}$, ocean productivity, ocean circulation, global ice volumes and much more. Shells of living organisms have the unique capacity to control the morphology, crystal size, polymorphism, and structure of the inorganic material. These unusual properties have recently attracted the attention of numerous researchers, including both materials chemists and researchers in the medical and pharmaceutical sciences, because of biogenic origin and potential of these materials. Calcite and other carbonate minerals are very important minerals in the ocean ecosystems of the world.

Invertebrates, such as snails and bivalves have bio-mineralized properties (Lowenstam, 1954; Lowenstam and Weiner, 1989; Fratzl et al., 1992., Mann, 1983, 1996; Magdans and Gies, 2004). These properties have, potentially, a direct impact on materials science of the future, especially in regards to the creation of nano-structures by self-assembly. The mechanism of calcium carbonate and the associated bio-mineralization are considerable interest not only for a biologist, but also for materials scientists, geochemists and palaeontologists. But there are questions as how to interpret these clues, particularly in understanding how the shell structure has changed after the animal dies, over the millions of years, it lies in sediments. Describing and understanding these uncertainties is essential in interpreting and using environmental data derived from the diffraction patterns of the shells.

The future objectives are (:) (1) to develop multi scale tools for predicting mechanical behavior of biological materials by bridging molecular, micro to nano scale mathematical models: (2) to answer fundamental reasons for the extraordinary mechanical properties like toughness and strength exhibited by biological nano-composite samples: (3) to develop computational and analytical tools for a truly simulation based design of materials: (4) to predict the mechanical response of a variety of other biological materials for applications in Bio-engineering.

The complex structures from these samples, which has risen from millions of years of evolution, are inspiring material scientists in the design of novel materials. This research illustrates the biological structural properties of snails and bivalves. The growth and self-assembly of calcium carbonate found in many shells is a fascinating topic and still not completely understood process. Understanding the biological process in these samples in which living organisms control the growth and structure of inorganic materials could lead upto novel synthesis techniques for nano scale composites with high mechanical performances. Many hard biological materials such as shells and bivalves contain a mineral phase. A new direction consists of starting at the atomic / molecular level through self-assembly and proceeds up in the dimensional scale, incorporating the hierarchical complexity of biological materials (Pokroy et al., 2004, 2006a, 2006b). These new structures that have potential applications in a number of areas, including quantum dots, photonic materials, drug delivery, tissue engineering, and genetically engineered biomaterials. Single-crystalline structures, which are widely used in modern microelectronics and optoelectronics.

We applied the synchrotron-based diffraction to shells and bivalve characterization, bearing in mind that these samples possess complicated depth-dependent microstructures. These structures will be studied extensively with the use of powder diffraction techniques. Synchrotron-based technique relies on accurate measurement and simulation of the fine interference features of diffraction profiles in the vicinity of the Bragg angle. The profiles of lattice parameters, are routinely extracted by means of high-resolution synchrotron-based X-ray diffraction.

\section{Experimental}

Resonant and Diffraction beamline (P9) at Desy, Hamburg, Germany, is designed to operate the hard X-rays regime with energies ranging from 2.7 to $50 \mathrm{keV}$. Fig. 1 . shows the experimental system used by the authors. X-rays with an energy of $15 \mathrm{keV}$ $(\lambda=0.82666 \AA)$ were selected from the bending magnet source using a silicon double-crystal monochromator. The experimental hutch is dedicated to resonant X-ray scattering and general diffraction experiments. The focus size is $150 \times 40 \mu \mathrm{m}^{2}$ and the energy resolution is $<1.4 \mathrm{eV}$ with $\mathrm{Si}$ (111) and for $\mathrm{Si}$ (311) it is $<0.3 \mathrm{eV}$. The experimental hutch is equipped with a highly flexible and precise Psi-diffractometer with open Chi-circle. At the sample position, a simple goniometer mount, Displex cryostats or small sample environments, like ovens, can be mounted on the motorized xyz-translation stage. The detector arms consist of two translations separated by $25^{\circ}$. X-rays are detected using the area detector and mythen detector at an angle designated by the label $2 \theta$, referenced to the direct incoming beam. The magnitude of the momentum transfer ' $\mathrm{q}$ ' is a function of $2 \theta$, the scattering angle: $\mathrm{q}=(4 \pi / \lambda) \operatorname{Sin}(2 \theta / 2)$. The diffraction peaks presented in this work, varies upto $65^{\circ}\left(0<2 \theta<65^{\circ}\right)$, with a step of 0.02 degree at $5 \mathrm{~s} /$ step, with minimum sample tilts in the transverse direction. The data was converted to two- dimensional $2 \theta$ intensity data for the

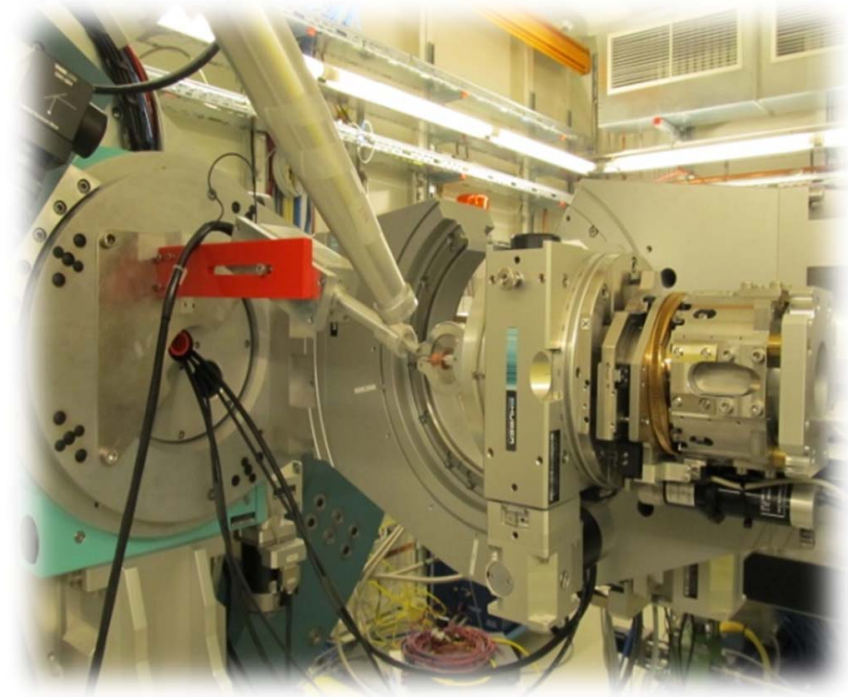

Fig. 1. Experimental system used by the author's at Desy: P9, diffraction beamline. 
analysis of the samples.

\section{Scanning electron microscopy}

Researchers studied, snail body parts, using SEM to magnify the features such as shell sculpture, radulae (teeth), reproductive organs and opercula, which will assist with identifying and classifying different spices. A high-resolution scanning electron microscope (HR-SEM, ULTRA Plus, Zeiss, Germany) was used for characterization of the crystal shape and morphology. To investigate the present samples, the SEM was operated at an accelerating voltage of $20 \mathrm{kV}$ and current of $10 \mathrm{~mA}$ for imaging and the associated morphology.

\section{Samples}

For the powder XRD technique, powder samples are prepared in the form of a pellet. Pressed pellets were prepared from snail and bivalve shells, with varying dimensions. Utilized the pressed pellets of external shell, operculum, and soft-tissue for a snail and external for a bivalve. One of the main factors concerning these samples is their unique properties and their irreplaceable nature. During the sample preparation for XRD, snail shells were occasionally washed with distilled water and by that procedure all possible impurities from inside and outside of the shells were removed. The physical dimension of the sample (snail and bivalve) and the area covered for preparation of the pellets, is mentioned in our earlier references, focused on imaging. The diameter of the shells varied from 0.5 to $10 \mathrm{~mm}$, and 0.25 to $0.5 \mathrm{~mm}$ thick. Regarding biological applications, we have investigated the distribution of elements in a small snail shell with the use of synchrotron-based, micro-beam X-ray fluorescence spectrometry. We used the uncoated SEM samples, to avoid the effects of charging and poor resolution. These are aragonite crystallites on the top of the calcite, which are spatially separated on the surface, with a small area. Analysis of the small area is better suited to establish the physiology and morphology of metals in specific structures like small animal shells and the distribution of trace elements. A spot size of $6 \mu \mathrm{m}$ (vertical) $\times 17 \mu \mathrm{m}$ (horizontal) was obtained by means of a K-B mirror arrangement. These properties provided a robust qualitative data about the behavior and effect of the mapped metals (Rao et al., 2009, 2010).

\section{Crystal structure}

Chemical Formula: $\mathrm{CaCO}_{3}$ : Composition: Molecular Weight $=100.09 \mathrm{gm}:$ Calcium $40.04 \%$ Ca $56.03 \%$ CaO, Carbon $12.00 \% \mathrm{C} 43.97 \% \mathrm{CO}_{2}$, Oxygen $47.96 \%$ O. Crystal System: Rhombohedral: point group 2/m, 2/m, 2/m: Space Group: pmon: The snail and bivalve has simple structure with four molecules of $\mathrm{CaCO}_{3}$ per orthorhombic unit shell $(a=4.9623, b=7.9682, c=5.7439 \AA, Z=4$ unit/cell, $V=226.85 \AA$, with axial ratios: a:b:c:0.6223:1:0.7205) (Dal Negro and Ungaretti, 1971; De Villiers, 1971).

\section{Results and discussion}

Table 1 shows the atomic parameters, positions and isotropic displacement parameters $(\AA)$ of atoms in orthorhombic carbonates and Table 2 shows, the Rietveld refinement (Rietveld, 1969). Tables 3 and 4, shows, the bond and atom groups. Tables 5-7, shows, the distances/angles and atom-wise symmetry operations for the sample of snail (EL+ST+OP and OP) and bivalve. The
Table 1

Atomic parameters, positions and isotropic displacement parameters ( $\mathrm{A}$ ) of atoms in orthorhombic carbonates.

\begin{tabular}{llllr}
\hline Atom & Wyckoff $x y z$ & $x$ & $y$ & \multicolumn{1}{l}{$z$} \\
\hline $\mathrm{Ca}$ & $4 \mathrm{c}$ & 0.00000 & 0.41508 & 0.75987 \\
$\mathrm{C}$ & $4 \mathrm{c}$ & 0.00000 & 0.76211 & -0.08518 \\
$\mathrm{O}(1)$ & $4 \mathrm{c}$ & 0.00000 & 0.92224 & -0.09557 \\
$\mathrm{O}(2)$ & $8 \mathrm{~d}$ & 0.47347 & 0.68605 & -0.08726 \\
\hline
\end{tabular}

Table 2

Parameters for the Rietveld refinement.

\begin{tabular}{ll}
\hline Parameters for the Rietveld refinement \\
\hline Energy $(\mathrm{E})$ & $15 \mathrm{keV}$ \\
Wavelength $(\lambda)$ & $0.82666(\AA)$ \\
Formula & $\mathrm{CaCO}_{3}$ \\
Cell parameters $(\AA)$ & $\mathrm{a}: 4.961982(1), \mathrm{b}: 7.9683(2), \mathrm{c}: 5.74239(1)$ \\
Molecular Weight $(\mathrm{g})$ & 100.09 \\
Volume & $226.85 \AA$ \\
System & Orthorhombic \\
Point group & $2 / \mathrm{m}, 2 / \mathrm{m}, 2 / \mathrm{m}$ \\
Space group & Pmcn $($ No: 62$)$ \\
Background & Polynomial type $($ sixth degree $)$ \\
Profile function & Pseudo-Voigt, 36 parameters, $(\Delta / \sigma)_{\max }=0.01$ \\
Final agreement factors & $\mathrm{R}_{\mathrm{P}}=0.982, \mathrm{R}_{\mathrm{wp}}=0.164, \mathrm{R}_{\mathrm{F}}=0.019, \mathrm{R}_{\mathrm{B}}=0.076$ \\
\end{tabular}

Table 3

Table of bond groups.

\begin{tabular}{llllll}
\hline $\begin{array}{l}\text { Number of bond } \\
\text { group }\end{array}$ & Symbol\#1 & Symbol\#2 & Connected & Dmin $(\AA)$ & Dmax $(\AA)$ \\
\hline 1 & Ca & Ca & Yes & 2.160 & 4.320 \\
2 & $\mathrm{Ca}$ & $\mathrm{C}$ & Yes & 1.500 & 3.000 \\
3 & $\mathrm{Ca}$ & $\mathrm{O}$ & Yes & 1.440 & 2.880 \\
4 & $\mathrm{C}$ & $\mathrm{C}$ & No & 0.828 & 1.656 \\
5 & $\mathrm{C}$ & $\mathrm{O}$ & Yes & 0.798 & 1.596 \\
6 & $\mathrm{O}$ & $\mathrm{O}$ & No & 0.888 & 1.776 \\
\hline
\end{tabular}

Table 4

Table of atom groups.

\begin{tabular}{lllll}
\hline No & Symbol & $\begin{array}{l}\text { Effective } \\
\text { radius }(\AA)\end{array}$ & $\begin{array}{l}\text { Drawing } \\
\text { radius }(\AA)\end{array}$ & $\begin{array}{l}\text { Van-der-Walls } \\
\text { radius }(\AA)\end{array}$ \\
\hline 1 & $\mathrm{Ca}$ & 1.8 & 0.570 & 2.600 \\
2 & $\mathrm{C}$ & 0.7 & 0.285 & 1.700 \\
3 & $\mathrm{O}$ & 0.6 & 0.255 & 1.520 \\
\hline
\end{tabular}

unique $\mathrm{C}-\mathrm{O}$ distances and $\mathrm{O}-\mathrm{C}-\mathrm{O}$ angles on the mirror plane are highlighted. Figs. 2-4 shows, XRD spectra from the powder sample of $\mathrm{EL}+\mathrm{ST}+\mathrm{OP}$, operculum and external shell of a bivalve with (a) raw spectrum (b) observed, calculated and differfence spectrum with Bragg reflections. Figs. 5 and 6 shows, XRD pattern for $(\mathrm{EL}+\mathrm{OP}+\mathrm{ST})$, and external shell of a bivalve, from Rietveld refinement with observed data (upper curve), difference $\mathrm{I}_{\mathrm{obs}}-\mathrm{I}_{\mathrm{cal}}$ (lower curve) and the vertical markers, show the calculated position for Bragg reflections. Experimental data has been compared with the calculated X-ray diffraction pattern of $\mathrm{CaCO}_{3}$. Measured points are indicated by continuous black line. The red line shows the calculated diffraction pattern and the blue line indicates the difference. 
Table 5

Distances/angles and atom-wise symmetry operations for the sample $\mathrm{EL}+\mathrm{ST}+\mathrm{OP}$.

\begin{tabular}{|c|c|c|c|c|c|c|c|}
\hline Atom 1 & Atom 2 & Symmetry op.2 & d 1,2 (A) Atom 3 Symmetry op.3 & Atom 3 & Symmetry op.3 & Angle $2,1 \ldots$ & d $1,3(\AA ̊)$ Angle $2,1 \ldots$ \\
\hline $\mathrm{Ca}$ & 01 & $0.5-x, 1.5-y, 0.5+z$ & 2.4122 & 011 & $-0.5+\mathrm{x}, 1-\mathrm{y},-\mathrm{z}$ & 2.4509 & 144.699 \\
\hline 011 & $\mathrm{C}$ & $\mathrm{x}, \mathrm{y}, \mathrm{z}$ & 1.2859 & $\mathrm{Ca}$ & $0.5+x, 1-y,-z$ & 2.4509 & 129.335 \\
\hline 011 & 01 & $x, y, z$ & 2.2238 & $\mathrm{Ca}$ & $0.5+x, 1-y,-z$ & 2.4509 & 124.547 \\
\hline 011 & 011 & $0.5-x, y, z$ & 2.2197 & $\mathrm{Ca}$ & $0.5+\mathrm{x}, 1-\mathrm{y},-\mathrm{z}$ & 2.4509 & 124.009 \\
\hline C & 01 & $\mathrm{x}, \mathrm{y}, \mathrm{z}$ & 1.2785 & 011 & $0.5-\mathrm{x}, \mathrm{y}, \mathrm{z}$ & 1.2859 & 120.263 \\
\hline 01 & $\mathrm{C}$ & $x, y, z$ & 1.2785 & $\mathrm{Ca}$ & $0.5-x, 1.5-y,-0.5+z$ & 2.4122 & 119.632 \\
\hline $\mathrm{C}$ & 011 & $x, y, z$ & 1.2859 & 011 & $0.5-x, y, z$ & 1.2859 & 119.333 \\
\hline 01 & 011 & $x, y, z$ & 2.2238 & $\mathrm{Ca}$ & $0.5-x, 1.5-y,-0.5+z$ & 2.4122 & 116.412 \\
\hline $\mathrm{Ca}$ & 011 & $-0.5+x, 1-y,-z$ & 2.4509 & 011 & $1-\mathrm{x}, 1-\mathrm{y},-\mathrm{z}$ & 2.4509 & 68.018 \\
\hline 011 & 011 & $0.5-x, y, z$ & 2.2197 & 01 & $\mathrm{x}, \mathrm{y}, \mathrm{z}$ & 2.2238 & 60.062 \\
\hline 01 & 011 & $0.5-x, y, z$ & 2.2238 & 011 & $x, y, z$ & 2.2238 & 59.879 \\
\hline 011 & $\mathrm{C}$ & $\mathrm{x}, \mathrm{y}, \mathrm{z}$ & 1.2859 & 011 & $0.5-x, y, z$ & 2.2197 & 30.334 \\
\hline 01 & $\mathrm{C}$ & $x, y, z$ & 1.2785 & 011 & $0.5-x, y, z$ & 2.2238 & 29.963 \\
\hline 011 & $\mathrm{C}$ & $\mathrm{x}, \mathrm{y}, \mathrm{z}$ & 1.2859 & 01 & $\mathrm{x}, \mathrm{y}, \mathrm{z}$ & 2.2238 & 29.774 \\
\hline
\end{tabular}

Table 6

Distances/angles and atom-wise symmetry operations for the sample of OP.

\begin{tabular}{|c|c|c|c|c|c|c|c|}
\hline Atom 1 & Atom 2 & Symmetry op.2 & d 1,2 (A) Atom 3 Symmetry op.3 & Atom 3 & Symmetry op.3 & Angle $2,1 \ldots$ & d $1,3(\AA)$ Angle $2,1 \ldots$ \\
\hline $\mathrm{Ca}$ & 01 & $0.5-x, 1.5-y, 0.5+z$ & 2.4122 & 011 & $1-\mathrm{x}, 1-\mathrm{y},-\mathrm{z}$ & 2.444 & 144.929 \\
\hline 011 & $\mathrm{C}$ & $\mathrm{x}, \mathrm{y}, \mathrm{z}$ & 1.2772 & $\mathrm{Ca}$ & $0.5+\mathrm{x}, 1-\mathrm{y},-\mathrm{z}$ & 2.444 & 129.137 \\
\hline 011 & 01 & $x, y, z$ & 2.2188 & $\mathrm{Ca}$ & $0.5+\mathrm{x}, 1-\mathrm{y},-\mathrm{z}$ & 2.444 & 124.396 \\
\hline 011 & 011 & $0.5-x, y, z$ & 2.1996 & $\mathrm{Ca}$ & $0.5+\mathrm{x}, 1-\mathrm{y},-\mathrm{z}$ & 2.444 & 123.767 \\
\hline $\mathrm{C}$ & 011 & $0.5-x, y, z$ & 1.2772 & 01 & $\mathrm{x}, \mathrm{y}, \mathrm{z}$ & 1.2785 & 120.491 \\
\hline 01 & $\mathrm{C}$ & $\mathrm{x}, \mathrm{y}, \mathrm{z}$ & 1.2785 & $\mathrm{Ca}$ & $0.5-\mathrm{x}, 1.5-\mathrm{y},-0.5+\mathrm{z}$ & 2.4122 & 119.632 \\
\hline $\mathrm{C}$ & 011 & $x, y, z$ & 1.2772 & 011 & $0.5-\mathrm{x}, \mathrm{y}, \mathrm{z}$ & 1.2772 & 118.876 \\
\hline 01 & 011 & $x, y, z$ & 2.2188 & $\mathrm{Ca}$ & $0.5-\mathrm{x}, 1.5-\mathrm{y},-0.5+\mathrm{z}$ & 2.4122 & 116.476 \\
\hline $\mathrm{Ca}$ & 011 & $1-\mathrm{x}, 1-\mathrm{y},-\mathrm{z}$ & 2.444 & 011 & $-0.5+\mathrm{x}, 1-\mathrm{y},-\mathrm{z}$ & 2.444 & 67.535 \\
\hline 011 & 011 & $0.5-x, y, z$ & 2.1996 & 01 & $\mathrm{x}, \mathrm{y}, \mathrm{z}$ & 2.2188 & 60.286 \\
\hline 01 & 011 & $x, y, z$ & 2.2188 & 011 & $0.5-x, y, z$ & 2.2188 & 59.429 \\
\hline 011 & $\mathrm{C}$ & $\mathrm{x}, \mathrm{y}, \mathrm{z}$ & 1.2772 & 011 & $0.5-x, y, z$ & 2.1996 & 30.562 \\
\hline 011 & $\mathrm{C}$ & $\mathrm{x}, \mathrm{y}, \mathrm{z}$ & 1.2772 & 01 & $\mathrm{x}, \mathrm{y}, \mathrm{z}$ & 2.2188 & 29.771 \\
\hline 01 & $\mathrm{C}$ & $x, y, z$ & 1.2785 & 011 & $0.5-\mathrm{x}, \mathrm{y}, \mathrm{z}$ & 2.2188 & 29.738 \\
\hline
\end{tabular}

Table 7

Distances/angles and atom-wise symmetry operations for the sample of bivalve.

\begin{tabular}{|c|c|c|c|c|c|c|c|}
\hline Atom 1 & Atom 2 & Symmetry op.2 & d 1,2 (Å) Atom 3 Symmetry op.3 & Atom 3 & Symmetry op.3 & Angle $2,1 \ldots$ & d 1,3 (Å) Angle 2,1. \\
\hline $\mathrm{Ca}$ & 01 & $0.5-x, 1.5-y, 0.5+z$ & 2.4122 & 011 & $1-\mathrm{x}, 1-\mathrm{y},-\mathrm{z}$ & 2.4509 & 144.699 \\
\hline 011 & $\mathrm{C}$ & $\mathrm{x}, \mathrm{y}, \mathrm{z}$ & 1.2859 & $\mathrm{Ca}$ & $0.5+x, 1-y,-z$ & 2.4509 & 129.335 \\
\hline 011 & 01 & $\mathrm{x}, \mathrm{y}, \mathrm{z}$ & 2.2238 & $\mathrm{Ca}$ & $0.5+\mathrm{x}, 1-\mathrm{y},-\mathrm{z}$ & 2.4509 & 124.547 \\
\hline 011 & 011 & $0.5-x, y, z$ & 2.2197 & $\mathrm{Ca}$ & $0.5+x, 1-y,-z$ & 2.4509 & 124.009 \\
\hline $\mathrm{C}$ & 01 & $\mathrm{x}, \mathrm{y}, \mathrm{z}$ & 1.2785 & 011 & $0.5-x, y, z$ & 1.2859 & 120.263 \\
\hline 01 & $\mathrm{C}$ & $\mathrm{x}, \mathrm{y}, \mathrm{z}$ & 1.2785 & $\mathrm{Ca}$ & $0.5-\mathrm{x}, 1.5-\mathrm{y},-0.5+\mathrm{z}$ & 2.4122 & 119.632 \\
\hline $\mathrm{C}$ & 011 & $0.5-x, y, z$ & 1.2859 & 011 & $\mathrm{x}, \mathrm{y}, \mathrm{z}$ & 1.2859 & 119.333 \\
\hline 01 & 011 & $0.5-x, y, z$ & 2.2238 & $\mathrm{Ca}$ & $0.5-\mathrm{x}, 1.5-\mathrm{y},-0.5+\mathrm{z}$ & 2.4122 & 116.412 \\
\hline $\mathrm{Ca}$ & 011 & $1-\mathrm{x}, 1-\mathrm{y},-\mathrm{z}$ & 2.4509 & 011 & $-0.5+\mathrm{x}, 1-\mathrm{y},-\mathrm{z}$ & 2.4509 & 68.018 \\
\hline 011 & 011 & $0.5-x, y, z$ & 2.2197 & 01 & $\mathrm{x}, \mathrm{y}, \mathrm{z}$ & 2.2238 & 60.062 \\
\hline 01 & 011 & $x, y, z$ & 2.2238 & 011 & $0.5-x, y, z$ & 2.2238 & 59.879 \\
\hline 011 & $\mathrm{C}$ & $\mathrm{x}, \mathrm{y}, \mathrm{z}$ & 1.2859 & 011 & $0.5-x, y, z$ & 2.2197 & 30.334 \\
\hline 01 & $\mathrm{C}$ & $\mathrm{x}, \mathrm{y}, \mathrm{z}$ & 1.2785 & 011 & $0.5-x, y, z$ & 2.2238 & 29.963 \\
\hline 011 & $\mathrm{C}$ & $x, y, z$ & 1.2859 & 01 & $x, y, z$ & 2.2238 & 29.774 \\
\hline
\end{tabular}

The X-ray diffraction pattern exhibits characteristic peaks of $\left(\mathrm{CaCO}_{3}\right)$ at $2 \theta$ values of, $11.5^{\circ}, 26.34^{\circ}, 33.24^{\circ}$, and $45.98^{\circ}$ respectively, which correlate with (hkl) indices of (102), (111), (012), (221). These are the strongest peaks observed in the X-ray diffraction patterns of the analyzed samples. However, peaks are also observed at $27.71^{\circ}, 26.87^{\circ}, 27.02^{\circ}, 27.38^{\circ}, 27.57^{\circ}, 27.72^{\circ}, 41.28^{\circ}$, $45.62^{\circ}, 46.54^{\circ}, 48.84^{\circ}$ and $52.53^{\circ}$. Three high intensity peaks are located at $2 \theta=31.72^{\circ}, 32.32^{\circ}$ and $32.93^{\circ}$. It reflects, the majority of the observed reflections were attributed to calcium carbonate phase of orthorhombic symmetry (JCPDS file 41-1475).
All samples were characterized by XRD and their XRD patterns refined using the Rietveld method to quantify the phase transformation. X-ray diffraction (XRD) analysis indicated that all the samples were composed by crystalline and amorphous phases. Structural refinement was performed using the Rietveld method as implemented in the computer program package Fullprof-Suite (Rodriguez-Carvajal, 1989; Roisnel and Rodríguez-Carvajal, 2004). Although the external structure and the operculum is well established, the present study is focused on most common orthorhombic carbonate, occurs as the inorganic constituent of many 


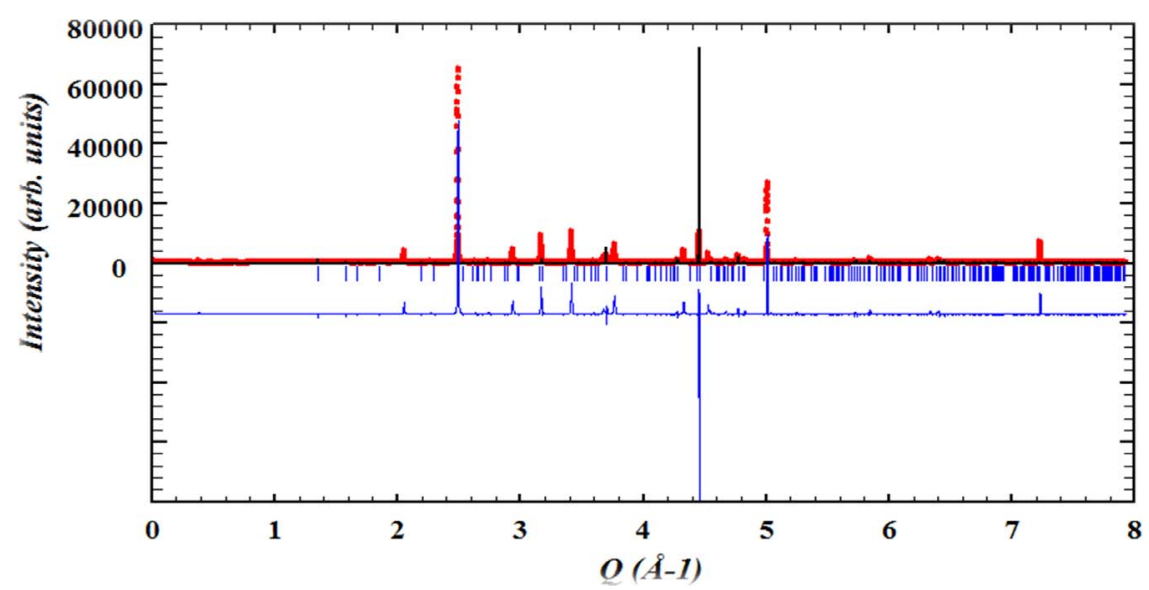

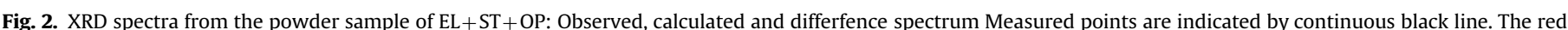

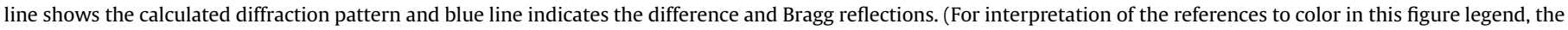
reader is referred to the web version of this article.)

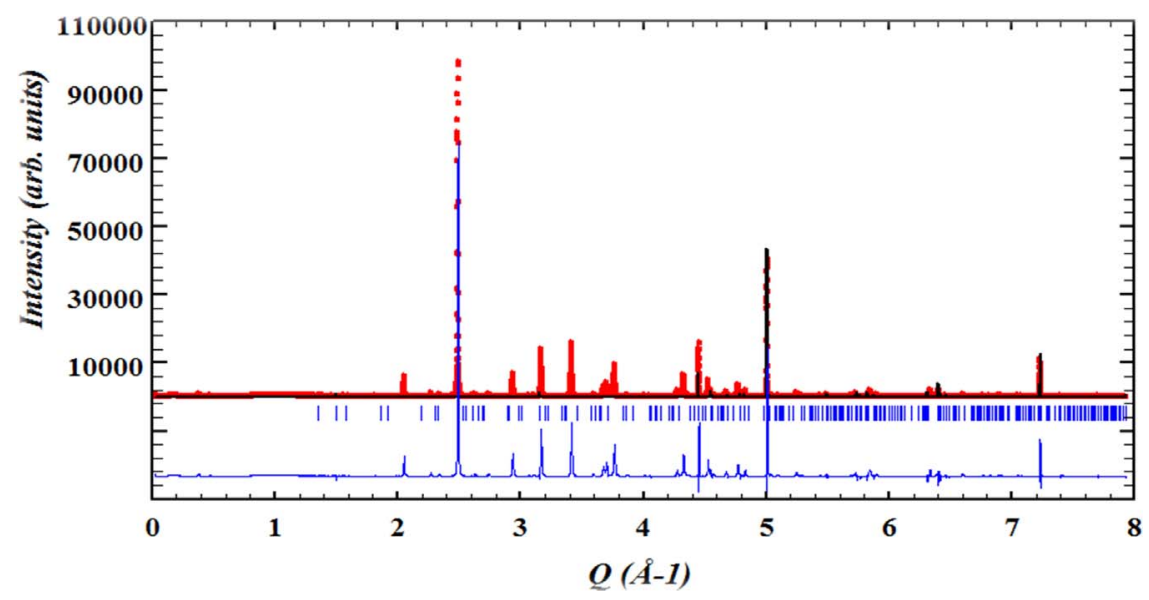

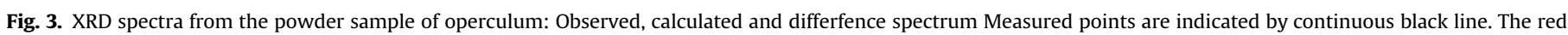

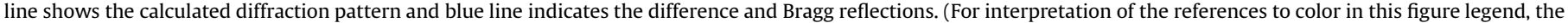
reader is referred to the web version of this article.)

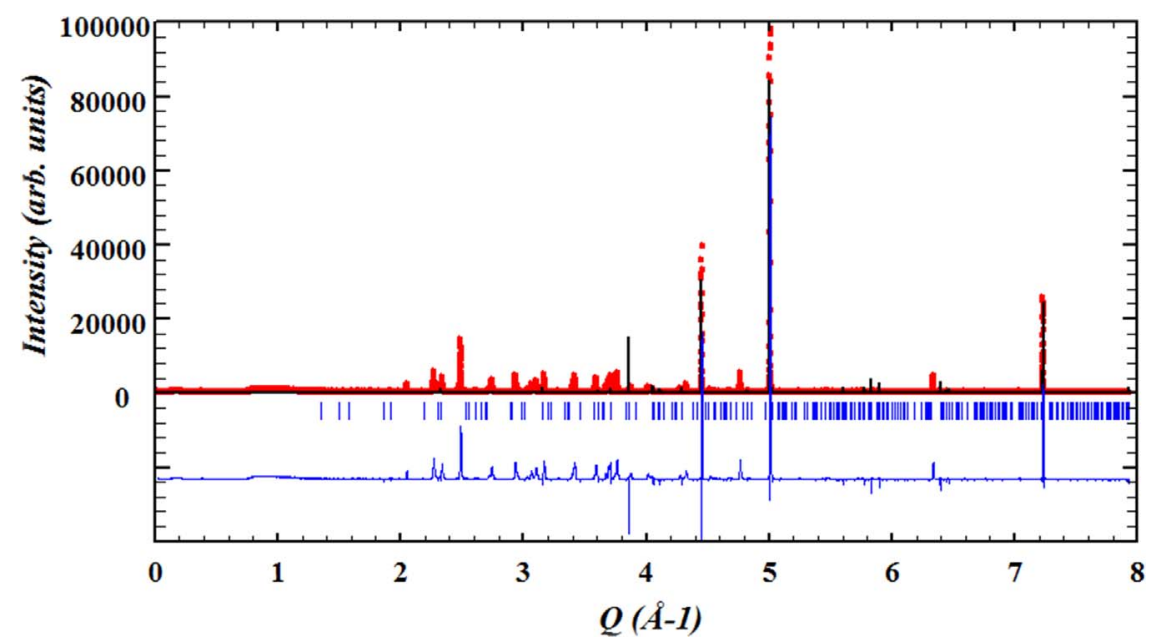

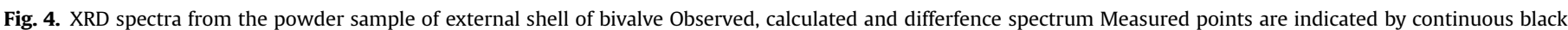

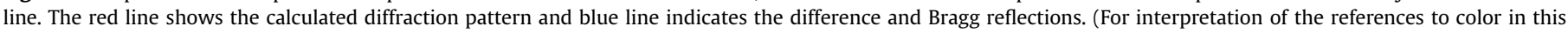
figure legend, the reader is referred to the web version of this article.) 


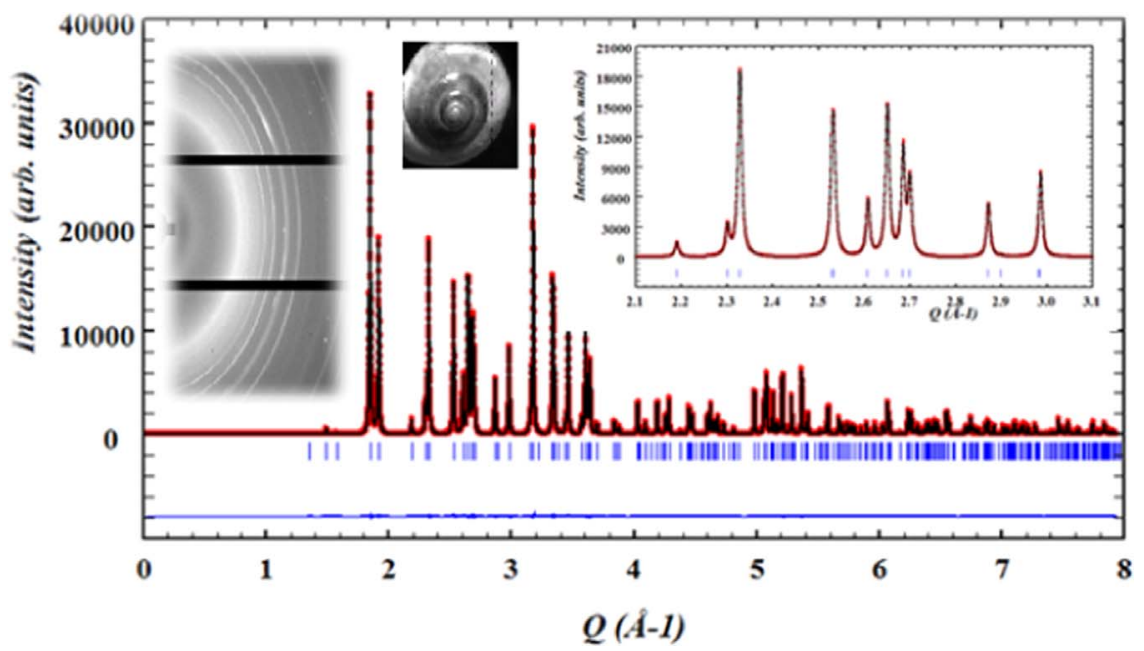

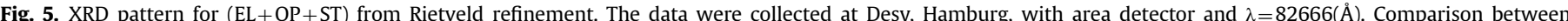

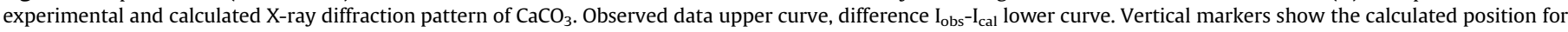

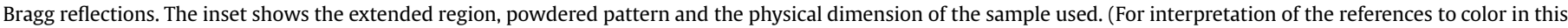
figure legend, the reader is referred to the web version of this article.)

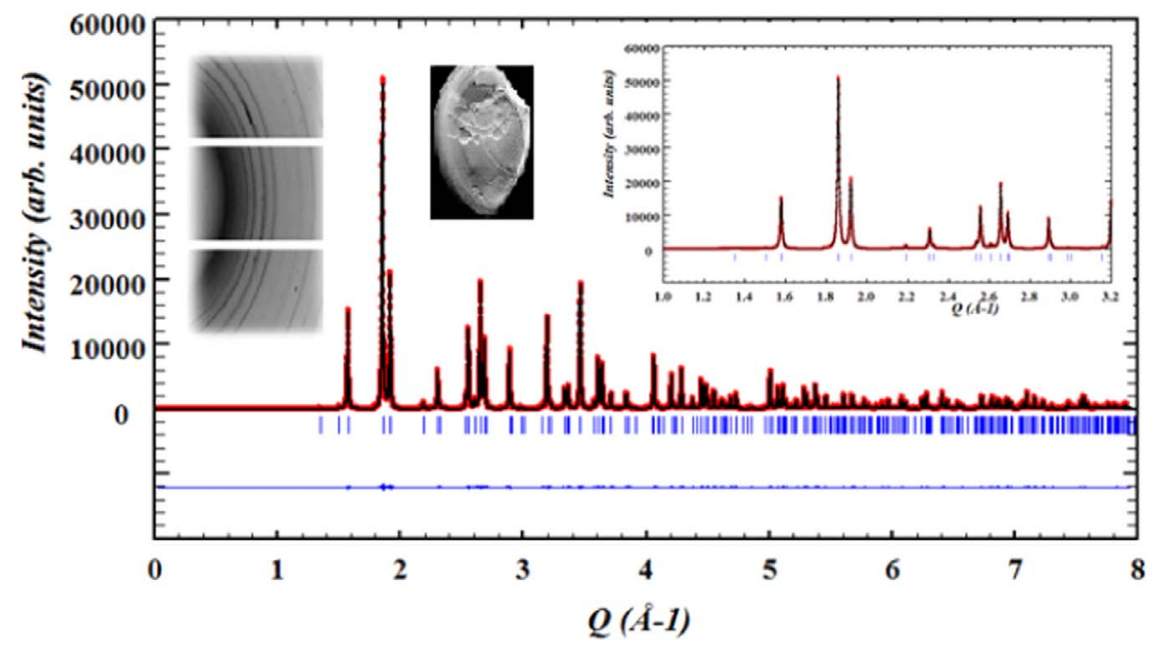

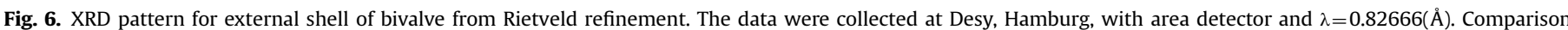

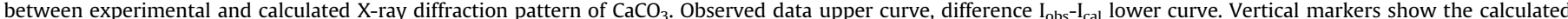

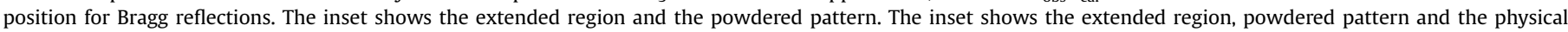
dimension of the sample used. (For interpretation of the references to color in this figure legend, the reader is referred to the web version of this article.)

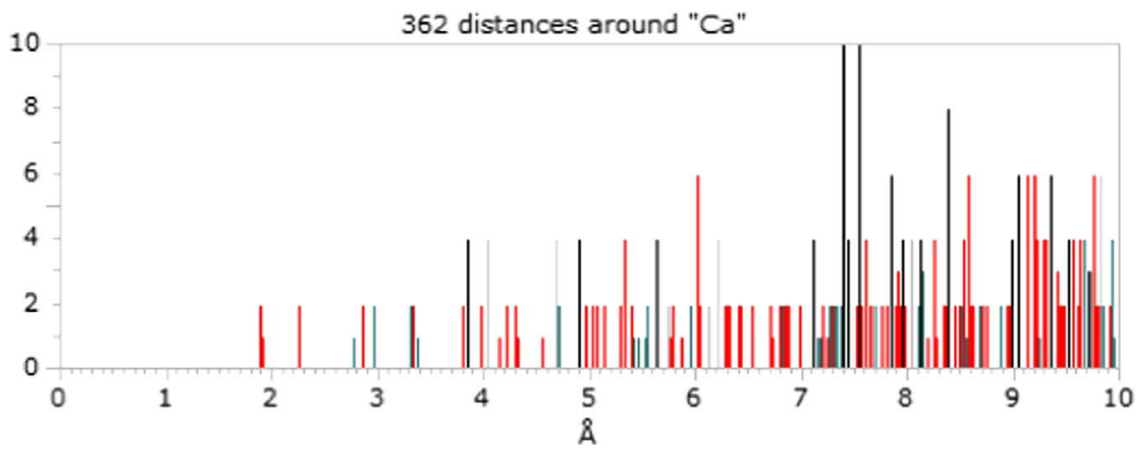

Fig. 7. The histogram shows the distances around Ca.

invertebrates skeletons and sediments derived from them. The structures of these samples were refined in space group Pmcn (No. 62 ) of orthorhombic structural model with the following atomic positions: $\mathrm{Ca}, \mathrm{C}$ and $\mathrm{O} 1$ at 4 (c) and $\mathrm{O} 2$ at 8 (d). The crystalline phases of the powders were identified by matching the XRD patterns with the Joint Committee on Powder Diffraction Standards 


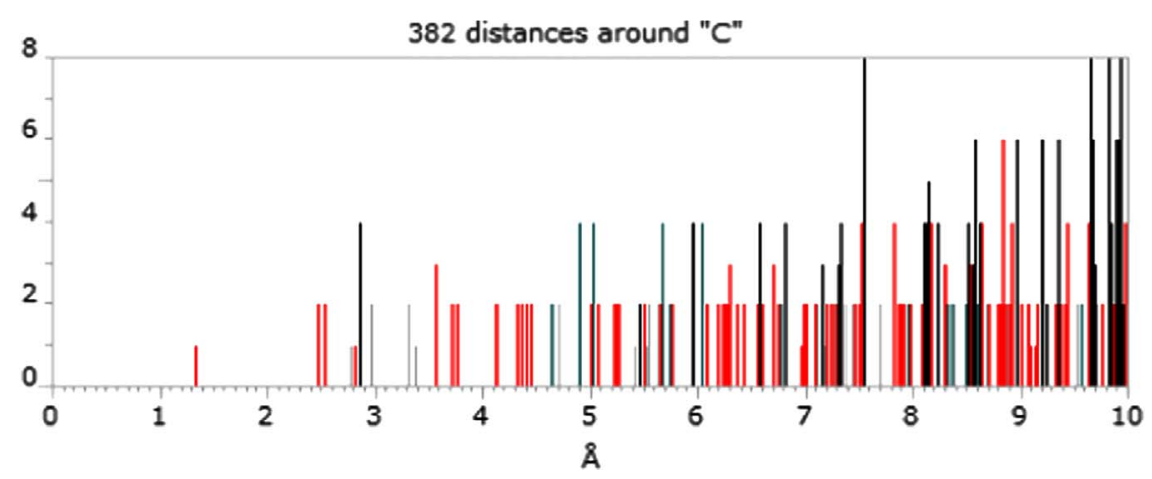

Fig. 8. The histogram shows the distances around C.

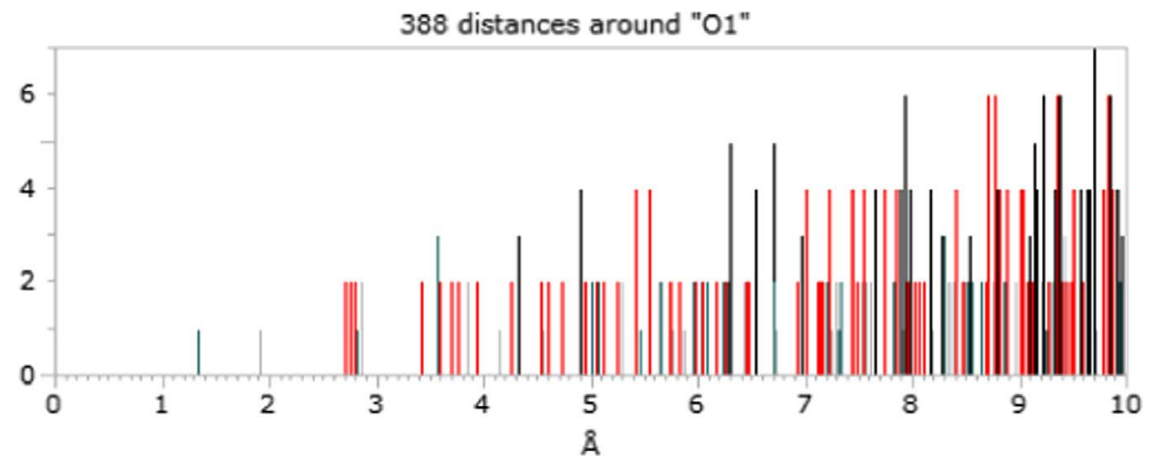

Fig. 9. The histogram shows the distances around 01 .

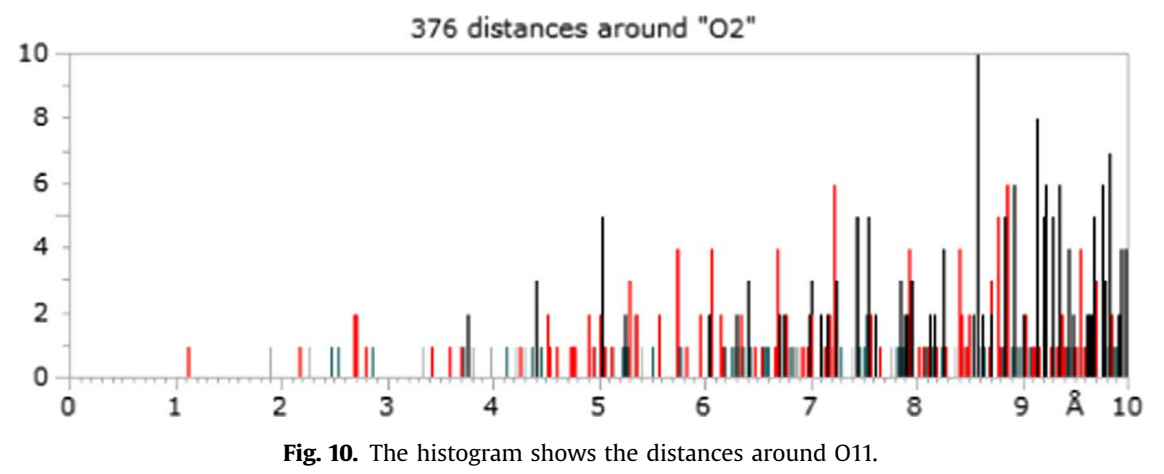

(JCPDS file 41-1475) database. The histograms are displayed in Figs. 7-10. The histogram of Ca-O1, shows, the distances of 362 around $\mathrm{Ca}$, for $\mathrm{Ca}-\mathrm{O} 1$, around 382 , for $\mathrm{O} 1-\mathrm{C}$, around 388, and for O11-C, around 376.

Synchrotron-based X-ray diffraction can be used to examine the internal structural features of the matter and in some circumstances, it can be used non-destructive manner. The crystallography of the samples and the associated morphology is presented in Figs. 11-13. The crystallographic connection, can be used to explore the unit cell of packed molecules as well as their degree of preferential arrangement (crystallinity). The term "crystallinity" is used to represent the crystallite size and lattice perfection. For example, in these shells, the closely assembled molecules tends to vary in directionality relative to the shell surface (cross-sectional image of shell).

Figs. 11-13, shows the atomic structure of $\mathrm{CaCO}_{3}$ [crystal structure of $(\mathrm{EL}+\mathrm{ST}+\mathrm{OP})$, operculum and bivalve] with a-axis lies almost vertical in the plane of view and c-axis is at vertical position. Results of powdered snail shells showed the mineralogy. The mineralogy differs according to locality and species indicating the influence of the environmental conditions on bio-mineralization processes in the inner inorganic layer and contents of minerals in the operculum and the shell layers of the snails. Because of its crystallographic properties calcite in the shell layers provides a better temperature protection of the organism from the environment.

Data obtained from the careful measurements, from the samples of snail and bivalve, shows the structure of orthorhombic, but the lattice parameters, a, b, and c, varies slightly, since animals live in geologically different conditions. From the updated diffraction data base (JCPDS file 41-1475), $\mathrm{CaCO}_{3}$, has an orthorhombic unit cell (space group pmcn (62)) with lattice parameters $\mathrm{a}=4.9623(\AA)$ ), $\mathrm{b}=7.968(\AA)$, and $\mathrm{c}=5.7439(\AA)$. The Rietveld refinement of the diffraction pattern yielded lattice parameters, a:4.961982(1), 


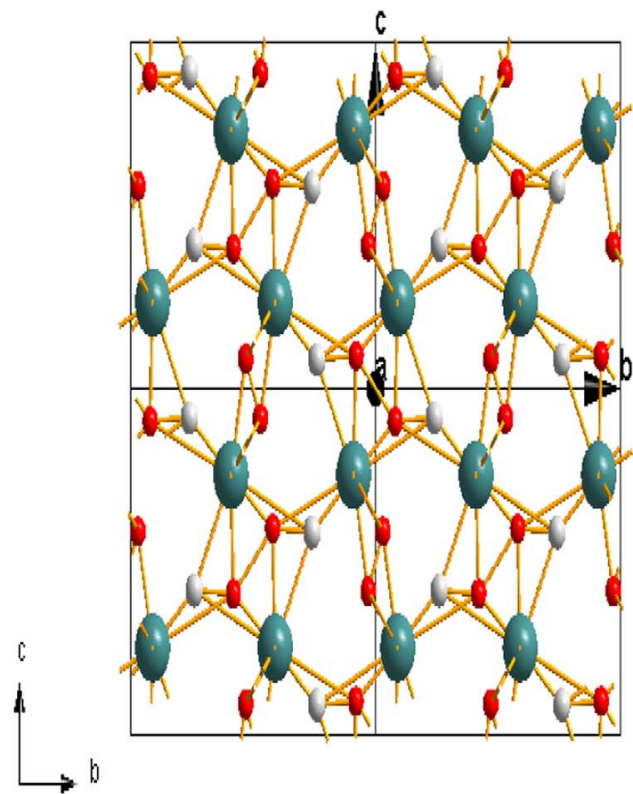

(a)

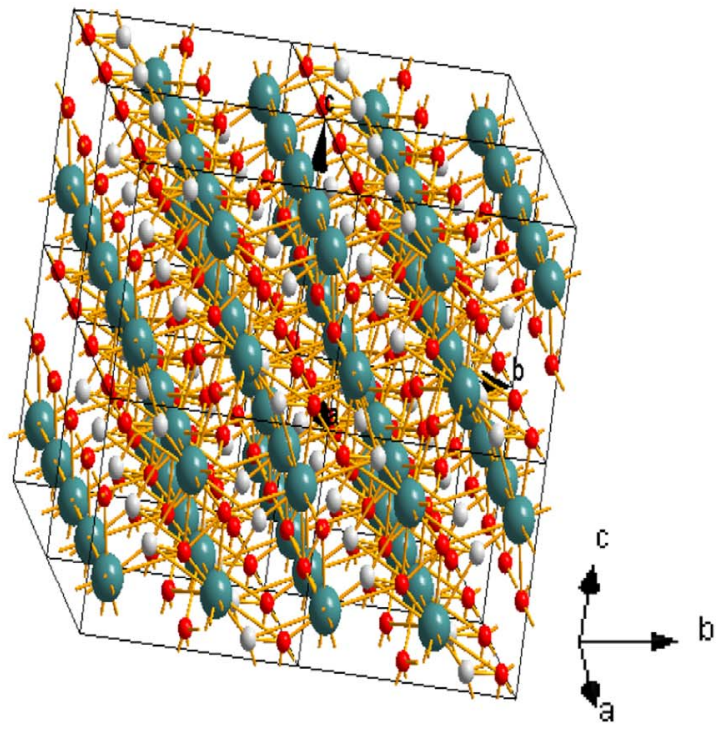

(b)

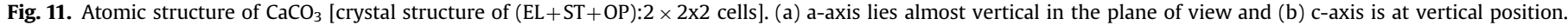

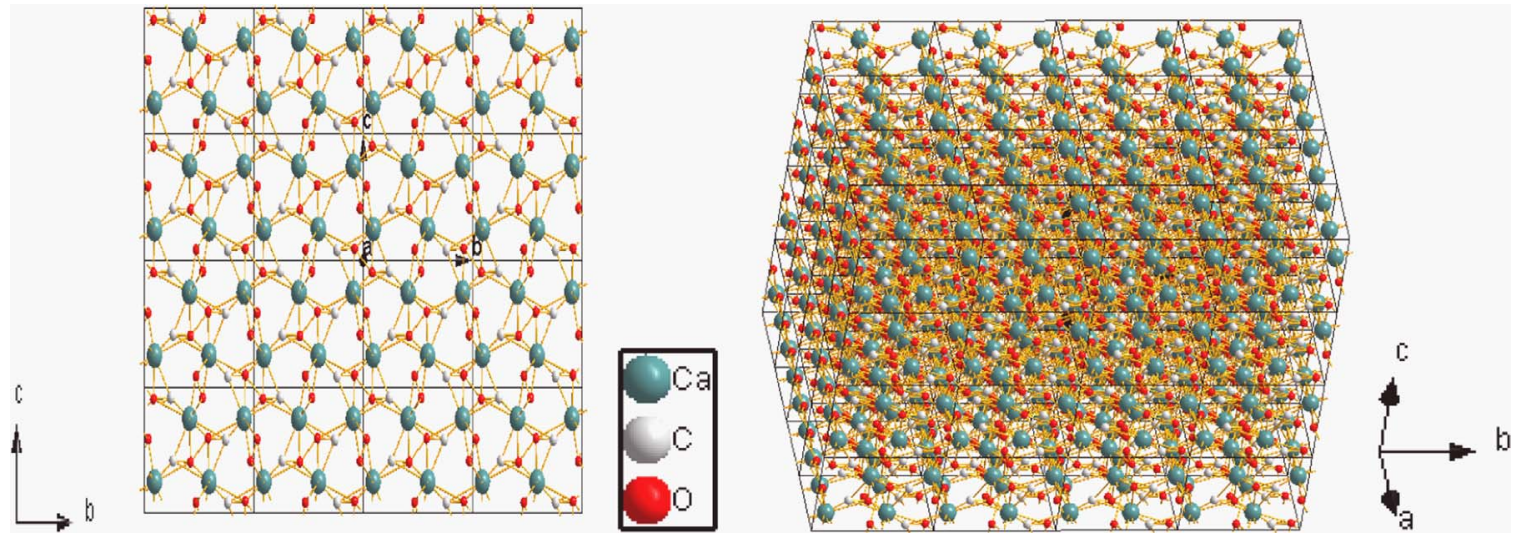

Fig. 12. Atomic structure of $\mathrm{CaCO}_{3}$ [crystal structure of (OP)]. (a) a-axis lies almost vertical in the plane of view and (b) c-axis is at vertical position.
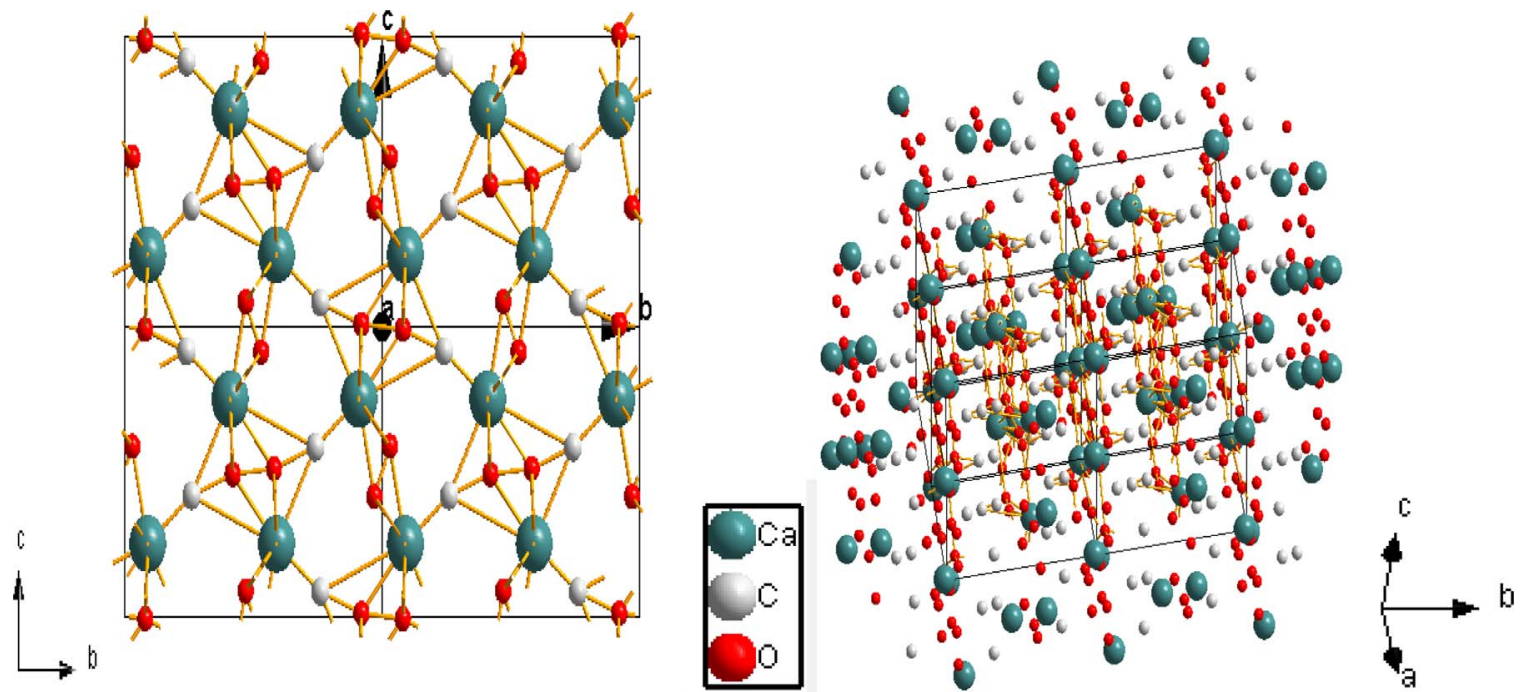

Fig. 13. Atomic structure of $\mathrm{CaCO}_{3}$ [crystal structure of (Bivalve:)]. (a) a-axis lies almost vertical in the plane of view and (b) c-axis is at vertical position. 


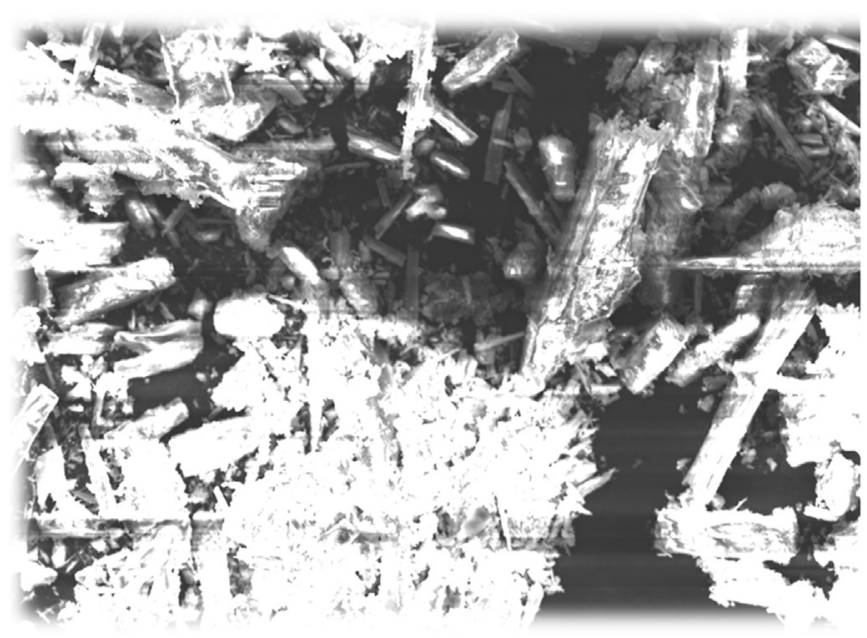

Fig. 14. External shell of a bivalve: $20 \mu \mathrm{m}$ : $E H T=15 \mathrm{kV}$ : WD:6.6 mm: Signal $\mathrm{A}=$ InLens: Mag:9.67 KX.

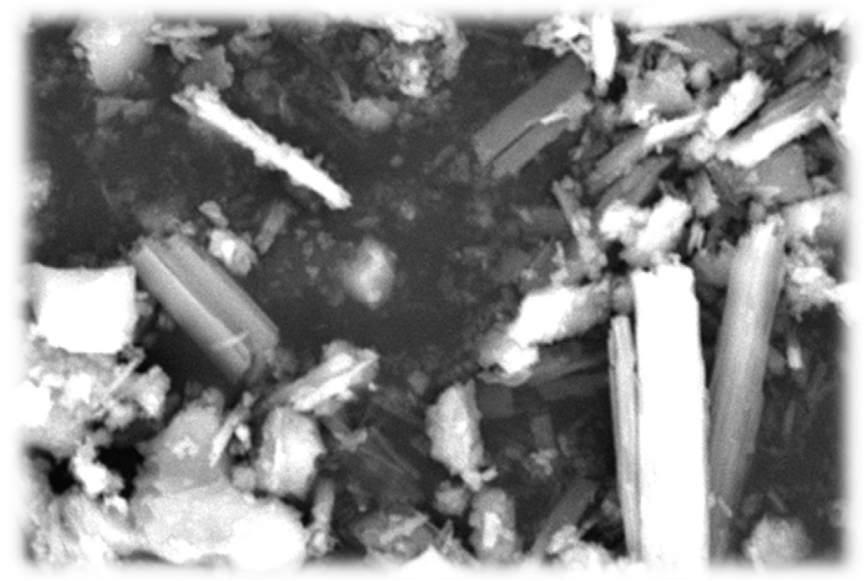

Fig. 15. OP: $2 \mu \mathrm{m}$ : $\mathrm{EHT}=20 \mathrm{kV}$ : WD:5.5 mm: Signal $A=$ InLens: Mag: $10.6 \mathrm{KX}$.

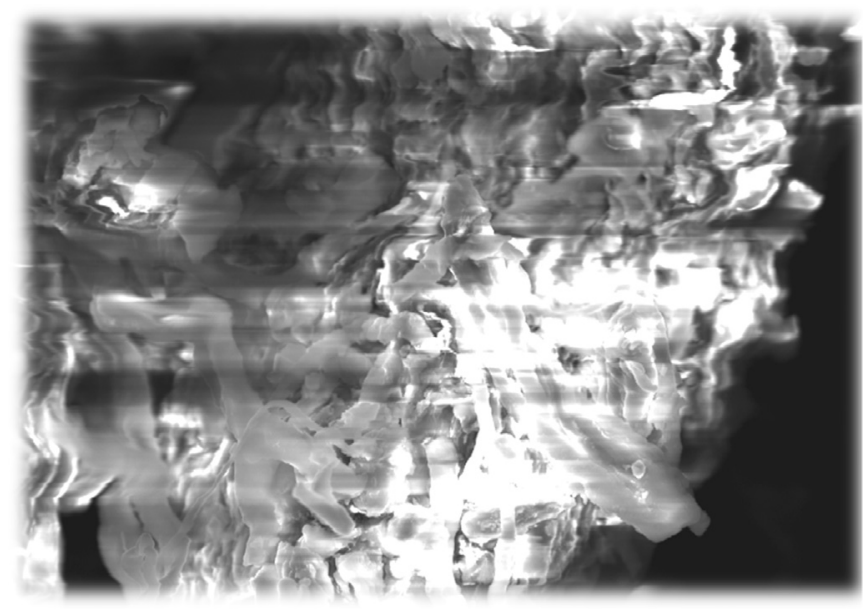

Fig. 16. $\mathrm{ST}: 10 \mu \mathrm{m}$ : $\mathrm{EHT}=15 \mathrm{kV}$ : WD: $4.8 \mathrm{~mm}$ : Signal $\mathrm{A}=$ InLens: Mag: $3.0 \mathrm{KX}$.

b:7.9683(2), c:5.74239(1), follows with the values reported by other researchers.

The microstructure and crystallography are analyzed through SEM. Figs. 14-17 shows, the images obtained with SEM, for EL, OP, ST and $E L+S T+O P$, at different settings, for the samples. Our scanning electron microscopy patterns show extremely small particle size of aragonite morphology of the crystalline, within the

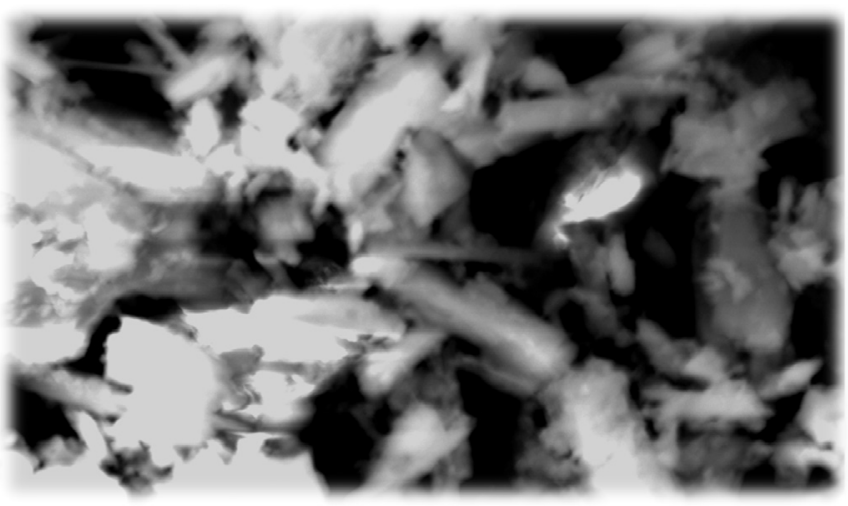

Fig. 17. $\mathrm{ES}+\mathrm{OP}+\mathrm{ST}: 2 \mu \mathrm{m}$ : $\mathrm{EHT}=15 \mathrm{kV}$ : WD:5.0 mm: Signal A=InLens: Mag: $12.98 \mathrm{KX}$.

shape and similar to those obtained from our X-ray powder diffraction Rietveld refinement . These images, reflect the consistent rhombohedral morphology of the individual samples, for example, external shell of the snail and bivalve have similar structures, at a resolution of $2 \mu \mathrm{m}$ and the image of the soft tissue has fibrous nature with a compact mesh structure at a resolution of $10 \mu \mathrm{m}$.

\section{Conclusions}

(1) Different degree of crystallization in bio-minerals is observed in a small animal shell and bivalve with the use of synchrotron-based X-ray diffraction techniques (2) The degree of orientation ordering in a small snail shell is much lower, compared to bivalve.

\section{Acknowledgments}

One of the authors (DVR) undertook part of this work with a support from, Department of Science Based Applications to Engineering, Universita di Roma "La Sapienza" (G-2016a), Via Scarpa 10, 00161, Roma, Italy, Istituto di Matematica e Fisica, Universita di Sassari (G-2016b), Italy, and Department of Bio-Systems Engineering, Yamagata University (G-2016c), Yonezawa, Japan. Experiments were performed at Desy, Hamburg, Germany, utilizing the Resonant and Diffraction beamline (P9). Travel support (DVR) received from DST window, Saha Institute of Nuclear Physics, India, under the category of utilization of Neutron and synchrotron facilities in aboard.

\section{References}

Bragg, W.L., 1924. The structure of aragonite. Proc. R. Soc. Lond. A 105, 16-39.

Dal Negro, A., Ungaretti, L., 1971. Refinement of the crystal structure of aragonite. Am. Miner. 56, 768-772.

De Villiers, J.P.R., 1971. Crystal Structures of aragonite, strontianite, and witherite. Am. Miner. 56, 758-767.

Fratzl, P., Groschner, M., Vogl, G., Plenk, H., Eschberger, J., Fratzlzelman, N., Koller, K., Klaushofer, K., 1992. J. Bone Miner. Res. 7, 329-334.

Jackson, A.P., Vincent, J.F., Turner, R.R., 1988. The mechanical design of nacre. Proc. R. Soc. Lond. B234, 415-440.

Kamat, S., Su, X., Ballarini, R., Heuer, A.H., 2000. Structural basis for the fracture toughness of the shell of the conch Strombus gigas. Nature 405, 1036-1040.

Lowenstam, H.A., 1954. Environmental relations of modification compositions of certain carbonate secreting marine invertebrates. Proc. Natl. Acad. Sci. USA 40, 39-48.

Lowenstam, H.A., Weiner, S., 1989. On Biomineralization. Oxford University Press, UK. Magdans, U., Gies, H., 2004. Single crystal structure analyses of sea urchin spine calcites. Eur. J. Miner. 16 (2), 261-268.

Mann, S., 1983. Mineralization in Biological systems. Struct. Bond. 54, 125-174. 
Mann, S., 1996. Biomineralization and biomimetic materials chemistry. In: Mann, S. (Ed.), Biomimetical Materials Chemistry. Wiley-VCH, Weinheim, pp. 1-40.

Pokroy, B., Quintana, J.P., Caspi, E.N., Berner, A., Zolotoyabko, E., 2004. Anisotropic lattice distortions in biogenic aragonite. Nat. Mater. 3, 900-902.

Pokroy, B., Fitch, A., Marin, F., Kapon, M., Adir, N., Zolotoyabko, E., 2006a. Anisotropic lattice distortions in biogenic calcite induced by intra-crystalline organic molecules. J. Struct. Biol. 155, 96-103.

Pokroy, B., Fitch, A., Lee, P., Quintana, J.P., Caspi, E.N., Zolotoyabko, E., 2006b. Anisotropic lattice distortions in mollusk-made aragonite: a widespread phenomenon. J. Struct. Biol., 145-150.

Rao, D.V., Swapna, M., Cesareo, R., Brunetti, A., Akatsuka, T., Yuasa, T., Takeda, T.,
Tromba, G., Gigante, G.E., 2009. Investigation of the distribution of elements in snail shell with the use of synchrotron-based, micro-beam X-ray fluorescence spectrometry. J. Trace Elem. Med. Biol. 23, 251-257.

Rao, D.V., Swapna, M., Cesareo, R., Brunetti, A., Akatsuka, T., Yuasa, T., Takeda, T., Tromba, G., Gigante, G.E., 2010. Use of synchrotron-based diffraction-enhanced imaging for visualization of soft tissues in invertebrates. Appl. Radiat. Isot. 68 (Issue 9), 1687-1693.

Rietveld, H.M., 1969. A profile refinement method for nuclear and magnetic structures. Appl. Crystallogr. 2, 65-71.

Rodriguez-Carvajal, J., 1989. 〈http://www-llb.cea.fr/fullweb/powder.htm〉. Roisnel, T., Rodríguez-Carvajal, J., 2001. Mater. Sci. Forum 378-3, 118-123. 